\title{
Comparison of Spectrophotometric Methods for Determination of Iron in Acid Cleaning, and Passivating Stainless Steel Solution by UV-VIS, ICP/MS, and FAAS
}

\author{
Yusuf Yildiz ${ }^{1, *}$, Recep Karadag ${ }^{2}$, Irmak Cengiz ${ }^{3}$ \\ ${ }^{1}$ John F. Kennedy Educational Complex, ACT Academy Science Department, Paterson NJ, USA \\ ${ }^{2}$ Istanbul Aydin University, Florya Campus Istanbul, Istanbul, Turkey \\ ${ }^{3}$ Chemical Engineering Department, Mersin University, Mersin, Turkey
}

Email address:

sayatoglu@yahoo.com (Y. Yildiz)

${ }^{*}$ Corresponding author

\section{To cite this article:}

Yusuf Yildiz, Recep Karadag, Irmak Cengiz. Comparison of Spectrophotometric Methods for Determination of Iron in Acid Cleaning, and Passivating Stainless Steel Solution by UV-VIS, ICP/MS, and FAAS. Science Journal of Analytical Chemistry.

Vol. 9, No. 2, 2021, pp. 32-38. doi: 10.11648/j.sjac.20210902.11

Received: April 8, 2021; Accepted: April 28, 2021; Published: May 8, 2021

\begin{abstract}
Generally, more sophisticated techniques such as, flame atomic absorption (AAS), inductively coupled plasma spectrometer (ICP-MS), and UV/Visible Spectrophotometer were used to determine trace iron metals in pickling (acid cleaning), and passivating stainless steel solutions. Simple and novel spectrophotometric methods are described for simultaneous determination of iron. While these techniques provide excellent sensitivity and selectivity. The results were found to be in satisfactory agreement (shows no significant difference) with those acquired by the flame atomic absorption spectrophotometer (FAAS), UV-Vis Spectrometer, and ICP/MS techniques. The results shows that the concentration of iron are very close each other (less than $5.0 \%$ ) in the pickling and passivating solutions.
\end{abstract}

Keywords: Acid Cleaning (Pickling) Solution, Passivating Solution, Iron Determination, ICP-MS, UV-VIS Spectrophotometer, and FAAS

\section{Introduction}

It is well known that iron is found in surface and drinking water and plays a vital role in biological systems and also it is the most abundant metal in the human body. Many proteins use iron for oxygen transport, electron transport, and as a catalyst in oxido-reductase reactions [1]. An excess of iron in a living cell can catalyze the production of reactive oxygen via the Fenton reaction, which damage lipids, nucleic acids, and proteins. Serious diseases such as Alzheimer's, Huntington's and Parkinson's result from the toxicity of iron ion $[2,3]$, so the concentration of iron becomes a parameter for the quality of drinking water [4].

Metal surface can contain impurities that may affect usage of the product or further processing like plating with metal or painting. Various chemical solutions are usually used to clean these impurities. Strong acids, such as hydrochloric acid and sulfuric acid are common, but different applications use various other acids. Also alkaline solutions can be used for cleaning metal surfaces. Solutions usually contain additives such as wetting agents and corrosion inhibitors. Pickling is sometimes called "acid cleaning" if descaling is not needed $[5,6]$.

Several analytical methods have been used for the determination of iron in aqueous solutions.

In this present work, a chromatic reagent of 1,10 phenanthroline is used for the determination of iron Fe (III) based on pickling and passivating stainless steel solutions by UV-Vis spectrometry, A Perkin Elmer 5100 PC atomic absorption spectrophotometer with deuterium arc background correction, and Inductively Coupled Plasma Spectrometer (ICP-MS) were used for determining of iron $(\mathrm{Fe})$ and comparing the results. 


\subsection{Acid Cleaning (Pickling)}

Pickling is a metal surface treatment process that removes impurities, such as stains, inorganic contaminants, rust or scale from ferrous metals, copper, precious metals and aluminum alloys [7]. A solution called "pickling" because it involves the use of an acidic solution known as pickle liquor [8], which usually contains acid, is used to remove the surface impurities. Mixture of nitric acid and hydrofluoric acids are usually used for pickling stainless steels. Stainless steel is composed of iron $(\mathrm{Fe})$, nickel $(\mathrm{Ni})$, chromium $(\mathrm{Cr})$, and several other minor components. Stainless steel is not resistant to chemical or physical attack. The corrosion resistance of stainless steel depends on the formation of a "passive surface film" composed of nickel and chromium oxides ( $\mathrm{Cr} 2 \mathrm{O} 3 \& \mathrm{NiO})$. Pickling involves metal removal and a charge or dulling in the visual brightness of the metal $[9,10]$. Pickling normally involves using an acid mixture containing $8-20$ vol\% nitric acid (HNO3) and $0.5-5$ vol\% hydrofluoric acid (HF). Chloride containing agents such as hydrochloric acid $(\mathrm{HCl})$ should be avoided $[11,12]$.

\subsection{Passivating Solution}

According to ASTM A 380, passivation is "the removal of exogenous iron or iron compounds from the surface of stainless steel by means of a chemical dissolution, most typically by a treatment with an acidic solution that will remove the surface contamination but will not significant effect the stainless steel itself." [12]. Passivating usually occurs naturally on the surfaces of stainless steels, but it may sometimes be necessary to assist the process with oxidizing acid treatments.

Passivating is the process by which a stainless steel will spontaneously form a chemically inactive surface when exposed to air or other oxygen-containing environments.

Passivating is the chemical treatment of a stainless steel with a mild oxidant, such as a nitric acid solution, for the purpose of enhancing the spontaneous formation of the protective film [12].

Safety

Pickling (acid cleaning) and passivating solutions use strong acids, and normal precautions for safety should be followed. All iron solutions should be discarded into a "Heavy Metals" waste container.

\section{Materials and Method}

\subsection{Determination of Iron by ICP/MS}

\subsubsection{Instruments}

1) NexIon 300X ICP-MS, Inductively Coupled Plasma computer-controlled sequential emission spectrometer with interelement and background correction capabilities, and provisions for interfacing to a printer and an auto sampler.

2) Ethos Plus Microwave

3) ETHOS One Closed Vessel Microwave Digestion
System, with temperature control and rotating turntable, well ventilated with corrosion-resistant cavity.

4) Microwave digestion vessels for water samples, Teflon, capable of holding $\sim 75$ milliliters $(\mathrm{mL})$, designed " for temperatures up to $260 \mathrm{C}$ with self-regulating pressure control

5) Digestion vessels for soil samples, capable of holding $\sim 250 \mathrm{~mL}$

6) Watch glasses or vapor recovery device

7) Glass dispensers, 2-liter (L), 1-L, or 1-gallon, checked quarterly for accuracy

8) Graduated Cylinder, Class A, $50 \mathrm{~mL}$

9) Volumetric flasks, Class A, assorted volumes

10)Balance, top-loading, capable of reading to 0.01 grams (g), for weighing digestion vessels before and after digestion

11)Henke SASS plastic syringes or equivalent

12)Corning SCFA 0.45 microns $(\mu \mathrm{m})$ filters or equivalent

13)Argon Plasma Support Gas in pressurized cylinders.

\subsubsection{Reagents and Solutions}

1) Concentrated nitric acid, Seastar Chemicals. 67-70\% (w/w $\mathrm{HNO}_{3}$ ), purified by re-distilled, $\geq 99.999 \%$ trace metals basis.

2) Nitric acid, 2 percent (\%) volume to volume (v/v), for the preparation of working standards, also to be used for the initial calibration blank.

3) Hydrogen peroxide solution contains inhibitor, were used in all procedures. 30 wt. $\%$ in $\mathrm{H}_{2} \mathrm{O}$, Sigma-Aldrich, ACS grade.

4) Pickling (Acid Cleaning) Stainless Steel Solution

5) Passivating Stainless Steel Solution

6) Deionized water, on the day of use. High-purity deionized water was obtained by Aries High Purity Water System, Aries Filter Works. Type I Deionized water, for the preparation of all reagents and calibration standards and as dilution water. Calibration curves were constructed using commercial Fe standards from analysis.

\subsubsection{Microwave Digestion}

Sample Preparation

$200 \mathrm{mg}$ of sample weighed and placed in each digestion vial. $8 \mathrm{~mL}$ of $\mathrm{HNO}_{3}$ nitric acid and $2 \mathrm{~mL}$ Hydrogen peroxide have been added to each vial including a blank. Tighten the vials in the vessels, twist the screw on top by hand and then use the teardrop ratchet to tighten further.

No sample was added in a vessel for the blank preparation. For the blank, line up the holes and ensure that the tube goes in. Place them in a microwave. After digestion; take out the vials from the microwave. The teardrop ratchet was used to loosen the vials from the vessels.

All the liquid from each digestion vial were transferred into $50 \mathrm{~mL}$ centrifuge tubes. About $10 \mathrm{~mL}$ Deionized (DI) water, Type I Water was added to wash and rinse the vials to make the total volume $20 \mathrm{~mL}$ using a $5 \mathrm{~mL}$ pipette. Digested sample were diluted with $1: 10,1: 100$, and 1: 1000 with 18.2 $\mathrm{M} \Omega-\mathrm{cm} \mathrm{H}_{2} \mathrm{O}$ and iron standards [13]. 
Table 1. Intensity of $\mathrm{Fe}$ by ICP/MS.

\begin{tabular}{lll}
\hline Standard Iron (Fe) Intensities & Standard Mode & \\
\hline 0.1 & 4805.5 & \\
1.0 & 7343.6 & Slope 514.7 \\
2.0 & 8103.0 & Intercept 5981.8 \\
10.0 & 10142.3 & $\mathrm{R}^{2}=0.99789$ \\
50.0 & 32131.1 & \\
100.0 & 57318.8 & \\
\hline
\end{tabular}

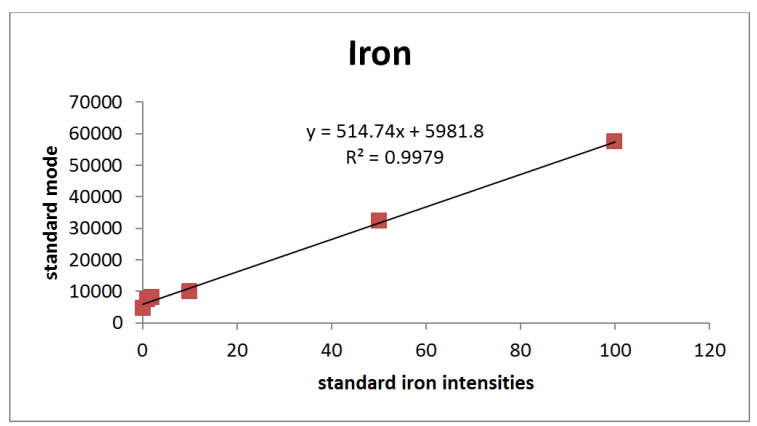

Figure 1. Calibration curve of Iron by ICP/MS.

Table 2. Intensity of samples.

\begin{tabular}{lllll}
\hline Standard Mode & & & & Iron \\
\hline Sample & Weight $(\mathbf{g})$ & Volume (L) & Dilution & Intensity \\
\hline Acid Cleaning & 0.2022 & 0.020 & 10 & 213792.9 \\
& 0.2022 & 0.020 & 10 & 219107.2 \\
& 0.2022 & 0.020 & 100 & 20653.3 \\
& 0.2022 & 0.020 & 100 & 20213.0 \\
& 0.2022 & 0.020 & 1000 & 2085.2 \\
Passivating & 0.2022 & 0.020 & 1000 & 2122.8 \\
& 0.2057 & 0.020 & 10 & 39.0 \\
& 0.2057 & 0.020 & 10 & 35.7 \\
& 0.2057 & 0.020 & 100 & 48.0 \\
& 0.2057 & 0.020 & 100 & 41.3 \\
& 0.2057 & 0.020 & 1000 & 34.3 \\
& 0.2057 & 0.020 & 1000 & 42 \\
& 0.2057 & 0.020 & 1000 & 6000 \\
\hline
\end{tabular}

Table 3. Intensity of Iron (cont.).

\begin{tabular}{lllll}
\hline $\begin{array}{l}\text { Conc (diluted), } \\
\mathbf{u g} / \mathbf{L}\end{array}$ & $\begin{array}{l}\text { Conc (undiluted), } \\
\mathbf{u g} / \mathbf{L}\end{array}$ & $\begin{array}{l}\text { Amount } \\
(\mathbf{u g})\end{array}$ & $\begin{array}{l}\text { Conc } \\
(\mathbf{u g} / \mathbf{g})\end{array}$ & Mean \\
\hline 403.7 & 4037.2 & 80.7 & 399.3 & \\
414.0 & 4140.5 & 82.8 & 409.5 & \\
28.5 & 2850.3 & 57.0 & 281.9 & \\
27.6 & 2764.8 & 55.3 & 273.5 & 277.7 \\
-7.6 & -7570.1 & -151.4 & -748.8 & \\
-7.5 & -7497.0 & -149.9 & -741.5 & \\
-11.5 & -115.5 & -2.3 & -11.2 & \\
-11.6 & -115.5 & -2.3 & -11.2 & \\
-11.5 & -1152.8 & -23.1 & -112.1 & \\
-11.5 & -1154.1 & -23.1 & -112.2 & \\
-11.6 & -11554.5 & -231.1 & -1123.4 & \\
-11.5 & -11539.5 & -230.8 & -1122.0 & \\
0.0 & 35.4 & 0.7 & 3.4 & $<5$ \\
\hline
\end{tabular}

\subsection{Iron with 1,10-Phenanthroline by UV-Vis Spectrophotometer}

1,10-Phenanthroline (phen), is organic bases chemical (Figure 2) react rapidly with $\mathrm{Fe}^{2+}$ ions in weakly acid media to give orange-red which are a basis for determining Fe(II). Iron (II) and total iron can be determined with phenanthroline after reduction of $\mathrm{Fe}$ to $\mathrm{Fe}(\mathrm{II})$. Hydroxylamine reduces $\mathrm{Fe}$ (III) within a few minutes in a weakly acidic medium ( $\mathrm{pH} 3-$ 4). The complex of 1,10-phenanthroline with $\mathrm{Fe}(\mathrm{II})$ is called ferroin and has been widely used in titrimetric analysis as a redox indicator. The compound 1,10-phenanthroline, $\mathrm{P}$, is a bidentate ligand with the following structure.

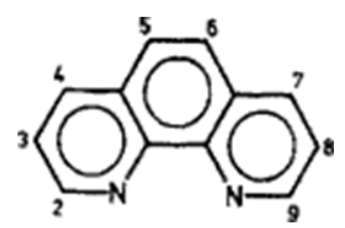

Figure 2. 1,10-Phenanthroline.

\subsubsection{Instrument}

UV/Visible spectrophotometers are widely used by many laboratories including those in academia and research as well as industrial quality assurance. The technique is mainly used quantitatively. The absorbance spectra for all measurements were carried out using a Shimadzu 1601 PC double beam UV-VIS Spectrophotometer, with $1 \mathrm{~cm}$ quartz cells and 2.0 $\mathrm{nm}$ fixed slit width. The spectrophotometer was connected to a computer, loaded with Shimadzu UVPC software, and equipped with an Epson LQ-850 printer [9, 14, 15].

\subsubsection{Chemicals and Equipment}

1) BioSpec-1601 UV-VIS Spectrophotometer

2) Several $100 \mathrm{~mL}$ and $1-500 \mathrm{~mL}$ volumetric flasks with corks or lids

3) 10.00 and 5.00 volumetric pipets

4) $1 \%$ Hydroxylamine $\mathrm{HCl}$ solution buffered with sodium acetate to $\mathrm{pH}=4.0$

5) Sodium acetate - acetic acid buffer at $\mathrm{pH}=4.0$

6) $0.2 \% 1,10$-phenanthroline solution

7) $3 \mathrm{M} \mathrm{H}_{2} \mathrm{SO}_{4}$

8) $10 \mathrm{mg} / \mathrm{L}(10.0 \mathrm{ppm})$ standard iron solution

9) Polythene bottle, about $25-\mathrm{ml}$ capacity (about $1 \mathrm{oz}$.)

10)1,10-Phenanthroline, powdered solid reagent.

\subsubsection{Procedure}

Determination of the Absorption Spectrum, max and the Molar Absorptivity Constant, for the Fe-orthophenanthroline complex.

1. 1. Prepare a $0.2 \%$ solution of 1,10 -phenanthroline in a $100.0 \mathrm{~mL}$ volumetric flask. Weigh out 0.2 grams of 1,10-phenanthroline and transfer it to a volumetric flask. Add $75.0 \mathrm{~mL}$ of distilled water to the flask, and then use a stir bar and magnetic stirrer to dissolve the compound. Remove the stir bar, and then dilute the solution up to the mark on the volumetric flask. You will need to stir this solution.

2. 2. Prepare serial Fe Standard Solutions; 0.05, 0.10, $0.15,0.20,0.25$, Blank in $50 \mathrm{~mL}$ VF

3. 3. Add $10 \mathrm{~mL} \mathrm{pH}=4$ Buffer, $5.0 \mathrm{~mL}$ of hydroxylamine $\mathrm{HCl}$, and $10 \mathrm{~mL}$ of $0.2 \%$ phenanthroline solution. Allow 15 minutes after adding all the reagents so that the color of the complex can fully develop before making any absorption measurements, bsorbance values $\mathrm{at}_{\max } 510 \mathrm{~nm}$ wavelength. 


\subsubsection{Experimental}

A Shimadzu 1601 PC UV/Vis spectrophotometer with matching 10-mm quartz cells was used for reading all spectra. All chemicals were of analytical grade and were used without further purification. Distilled, deionized water was used for making dilutions and for preparing all aqueous solutions [16].

In this experiment, the amount of iron present in a sample is determined by first reacting the iron with 1,10-Phenanthroline to form a colored complex and measuring the amount of light, absorbed by this complex. Beer's law can then be used to determine the concentration relative to absorption:

$$
\mathrm{A}=\alpha \mathrm{bc}
$$

To form a complex, the iron must be first reduced to its ferrous state. This reduction is done by reaction the iron with hydroxylamine Hydrochloride by the following reaction:

$$
2 \mathrm{Fe}^{2+}+2 \mathrm{NH}_{2} \mathrm{OH}+2 \mathrm{OH}^{-} \rightarrow 2 \mathrm{Fe}^{2+}+\mathrm{N}_{2}+4 \mathrm{H}_{2} \mathrm{O}
$$

Then the reaction with 1,10-Phenanthroline is:

$$
\left[\mathrm{Fe}(\text { Phen })_{3}\right]^{3+}+\mathrm{e}\left[\mathrm{Fe}(\text { Phen })_{3}\right]^{2+}
$$

Once a colored complex is formed, the wavelength of light which is most strongly absorbed is found by measuring the absorbance at variousWavelengts between 400-600 nm [17].

\subsubsection{Spectrophotometric Curves}

The spectrophotometric curves obtained for the standards and for the blank are shown in Table 4, and Table 5.
Deionized water was used as the blank. Since a faint redbrown color is produced by the reaction of iron and 1,10phenanthroline in slightly acid solutions, and requires up to 15 minutes for full color development.

The color was stable for one hour.

Table 4. Calibration Curve Data.

\begin{tabular}{llll}
\hline$[$ Fe] $(\mathbf{m g} / \mathbf{L})$ & Abs & Slope & $\mathbf{0 . 2 1 9 1}$ \\
\hline 0.00 & 0.0000 & Intercept & 0.0013 \\
0.05 & 0.0133 & $\mathrm{R}^{2}$ & 0.9978 \\
0.10 & 0.0234 & & \\
0.15 & 0.0353 & & \\
0.20 & 0.0450 & & \\
0.25 & 0.0553 & & \\
\hline
\end{tabular}

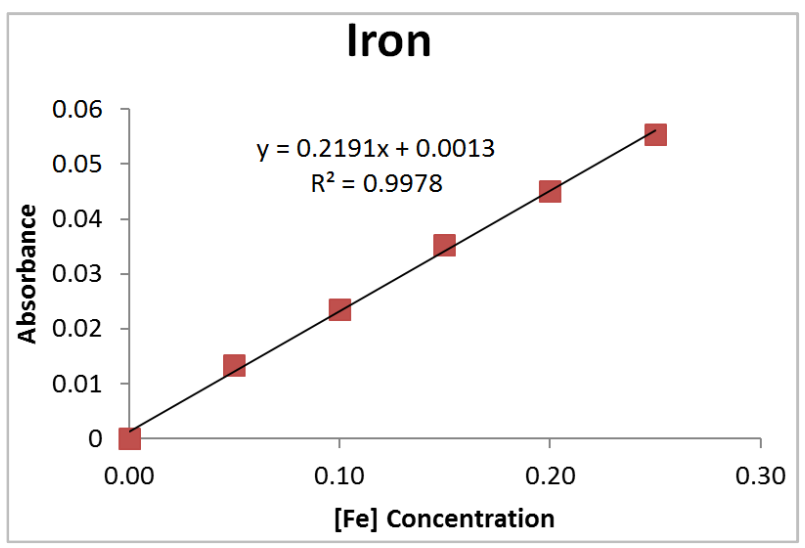

Figure 3. Calibration curve of Fe by UV-Vis Spectrophotometer.

Table 5. Lenear Calibration - Calculated in Excel.

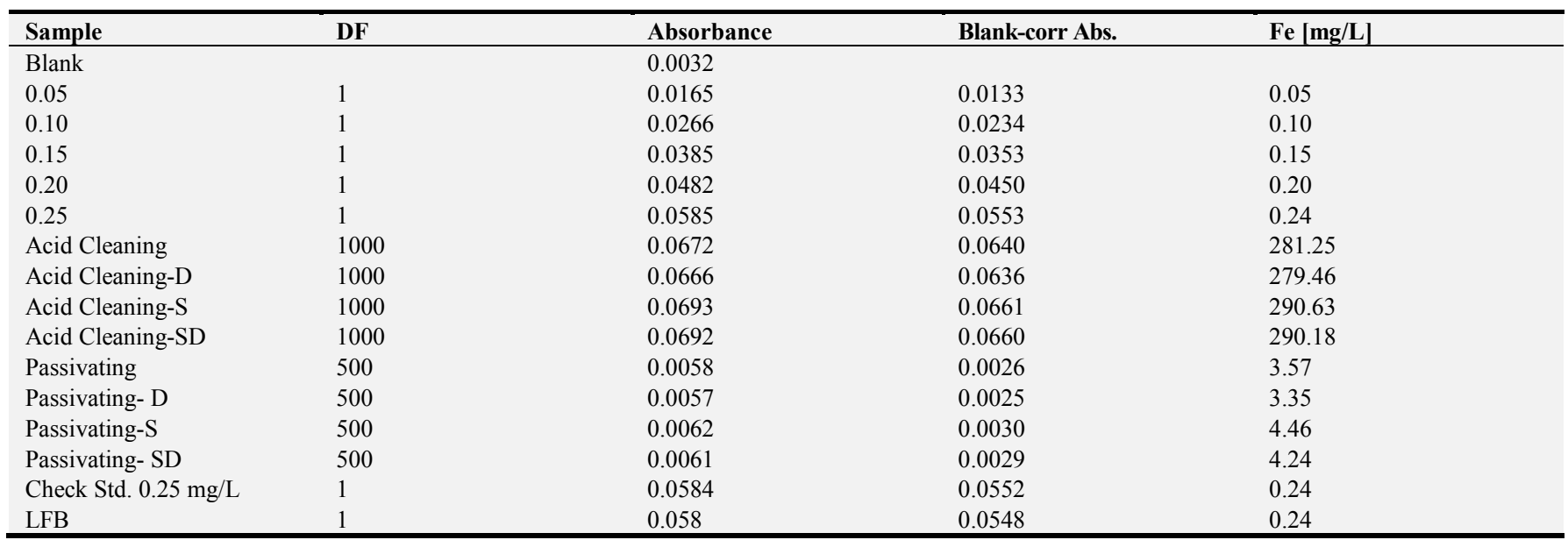

\subsection{Determination of Iron (Fe) by Atomic Absorption Spectrometry}

\subsubsection{Equipment/Instrument.}

1) Perkin Elmer A Analyst 200 model Flame Atomic Absorption spectrophotometer with Deuterium arc background correction was used for comparing the results.

2) Magnetic stirrer, with TFE-Coated Stirring.

3) Timer.

4) Lamps: Fe element hallow cathode lamp.

5) Glassware: All glassware is washed in the following sequence: Alconox detergent solution, tap water, 1:1 nitric acid, tap water, $1 ; 1$; hydrochloric acid, tap water, and final rinse with deionized water.

6) Pipettes: 5, 10, 20, 50, 100, 200, 500, and $1000 \mu \mathrm{L}$ pipettes with disposable tips are used.

\subsubsection{Reagents and Solutions}

All chemicals were used of analytical grade. Doubly distilled deionized water was used in the preparations of solutions and used throughout. Stock solutions were kept in polypropylene bottles containing $1 \mathrm{~mL}$ concentrated nitric acid. 
1) Pickling (acid cleaning) Stainless Steel Solution, obtained from ARDE Inc. New Jersey-USA.

2) Passivating Stainless Steel Solution, obtained from ARDE Inc. New Jersey-USA

3) Deionized water, on the day of use. Water was purified using a Millipore Mill-Q system via a pure water device marked Pure lab Option- Q7BP.

4) Iron standard solution $(1000 \mu \mathrm{g} / \mathrm{mL})$ : Stock iron solution containing $\mu / \mathrm{mL}$ Fe (III) was prepared by dissolving appropriate amounts of pure salt $\left(\mathrm{Fe}\left(\mathrm{NO}_{3}\right)_{3} \mathrm{X}\right.$ $10 \mathrm{H} 2 \mathrm{O}$ ) in $100 \mathrm{~mL}$ of doubled distilled deionized water. The working solutions were prepared just before use by dilution of the standard solution with redistilled deionized water. Standards should be prepared fresh daily. Prepare three to five standards covering the range. Pipet $25 \mathrm{~mL}$ of $1000 \mathrm{ppm}$ Certified Iron Standard Solution into a $250 \mathrm{~mL}$ volumetric flask. Add $10 \mathrm{~mL}$ of concentrated $\mathrm{HCl}$. Dilute to volume with deionized water and mix well [18].

Prepare AA standards for iron of 1.0, 3.0, 5.0, 7.0, and $10.0 \mathrm{mg} / \mathrm{L}$ with double distilled deionized water.

\subsubsection{Instrument/ Operation Parameters}

1) Blank: $100 \mathrm{~mL}$ of D. I. water is taken through the digestion process

2) Duplicate: A separate aliquot of random sample is digested or analysis (approximately 10\%).

3) Spike: Using the formula $\mathrm{C}_{1} \mathrm{~V}_{1}=\mathrm{C}_{2} \mathrm{~V}_{2}$ an appropriate volume and concentration of standards is brought through spiked into a sample and digestion procedure.

4) Instruments: Perkin-Elmer 5100 PC Atomic Absorption Spectrophotometer

5) Start Program: Perkin-Elmer 5100 PC Atomic Absorption Spectrum

6) Wavelength: $248.3 \mathrm{~nm}$ - UV

7) Slit width: $0.2 \mathrm{~nm}$

8) Relative sensitivity: $1.0 \mu \mathrm{g} / \mathrm{mL}$

9) Lamp energy: 67.0

10)Lamp Current: $5 \mathrm{~mA}$

11)Light sources: Hallow Cathode Lamp

12)Burner Head: Air-acetylene

13)Flame stoichiometry: Air-acetylene, oxidizing (lean, blue)

14)Integration Time: 1.5 seconds (for optimizing only)

15)Average Readings: 3

\subsubsection{Sample Preparation/Acid Digestion}

Pipette $1.0 \mathrm{~mL}$ of acid cleaning (Pickling) stainless steel solution and, $20 \mathrm{~mL}$ of passivation stainless steel solution transfer into a $100 \mathrm{~mL}$ of volumetric flask. Add approximately $25 \mathrm{~L}$ of D. I. water and mix well. Then add 10 $\mathrm{mL}$ of concentration hydrochloric acid and swirl to mix. Dilute to volume with D. I. water and mix well.

\section{Procedure}

1) Prepare AA standards for iron 1.0, 3.0, 5.0, 7.0, and $10.0 \mathrm{mg} / \mathrm{L}$ standard solutions.
2) Run AA for iron as follows. Blank the instrument with deionized water. Run water and then a standard. Run water then a sample. Continue until all standards and sample have been measured.

3) Subtract average water signal from each standard reading. Construct a calibration curve and report slope, intercept, and correlation coefficient.

4) Subtract average water signal from each sample reading. Calculate concentration using calibration slope and intercept.

5) Calculate $\mathrm{mg} / \mathrm{L}$ using the concentration in the volume taken, and the volume of solution.

\section{Experimental}

\subsection{Contamination Control}

All reagent were of a high purity grade. Eppendorf pipettes with plastic tips were used for all pipetting. All sample handling operations were conduct under a laminar flow hood to reduce atmospheric contamination.

\subsection{Calibration Standards}

The aqueous calibration standards were prepared in precleaned $100 \mathrm{~mL}$ volumetric flasks using pipettes and fixedvolume Effendorf pipette for volume transfers (Table 6 and Table 7). These standards represent the stock calibration standard were prepared.

\subsection{Backgrounds}

The technique of atomic absorption spectrometry (AAS) depends on generating a cloud of free atoms in the ground or unexcited state. The first AA spectrometers used a flame to generate atoms of the element to be determined [19]. The most common method of background correction in atomic absorption (AA) spectrophotometer uses a continuum source such as a deuterium lamp to measure the background. Background is electronically subtracted from total absorbance to give background corrected atomic absorbance [20].

\subsection{Calibration and Operation}

Before operation the calibration of the instrument is necessary. Rinse aspirator tube with D. I. water. Aspirate sample, ensure within range (between blank and highest standard). Dilute sample if necessary, and repeat for each sample.

Protocol:

Blank (purpose of this second blank measurement is to "zero" the reading)

Water

Standard

Water

Sample

Water

Sample dup

Water 
Matrix Spiked

Water

Matrix Spiked Duplicate

Water

Table 6. Calibration Curve Data.

\begin{tabular}{llll}
\hline$[\mathbf{F e}](\mathbf{m g} / \mathbf{L})$ & Abs & $\mathbf{m}$ & $\mathbf{0 . 0 1 8 6 3 3 8}$ \\
\hline 0.0 & -0.0007 & $\mathrm{~b}$ & 0.0009817 \\
1.0 & 0.0202 & $\mathrm{R}^{2}$ & 0.9992 \\
3.0 & 0.0591 & & \\
5.0 & 0.0940 & & \\
7.0 & 0.1306 & & \\
10.0 & 0.1786 & & \\
\hline
\end{tabular}

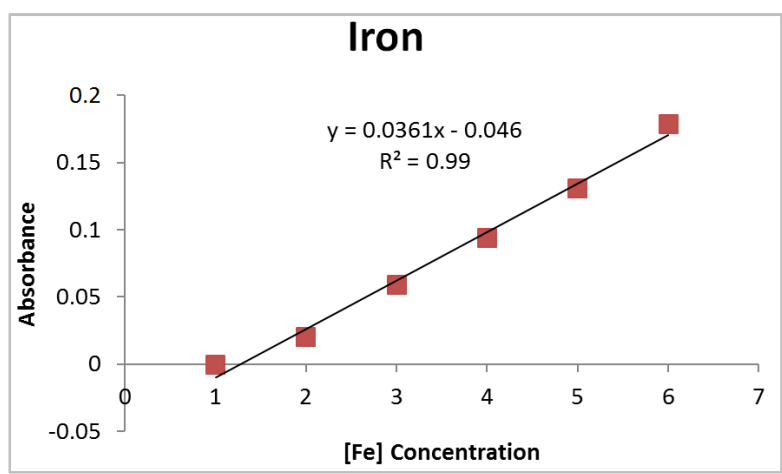

Figure 4. Calibration curve of Fe by AA.

Table 7. Linear Calibration-Calculated in Excel.

\begin{tabular}{|c|c|c|c|c|}
\hline Sample & DF & Absorbance & Blank Correction & {$[\mathrm{Fe}] \mathrm{mg} / \mathrm{L}$} \\
\hline Air & 1 & 0.0000 & & \\
\hline Water & 1 & 0.0036 & & \\
\hline Blank & 1 & 0.0000 & -0.0007 & -0.09 \\
\hline Water & 1 & 0.0038 & & \\
\hline $1 \mathrm{mg} / \mathrm{L}$ & 1 & 0.0249 & 0.0202 & 1.03 \\
\hline Water & 1 & 0.0056 & & \\
\hline $3 \mathrm{mg} / \mathrm{L}$ & 1 & 0.0648 & 0.0591 & 3.12 \\
\hline $5 \mathrm{mg} / \mathrm{L}$ & 1 & 0.1006 & 0.0940 & 4.99 \\
\hline Water & 1 & 0.0074 & & \\
\hline $7 \mathrm{mg} / \mathrm{L}$ & 1 & 0.1390 & 0.1306 & 6.95 \\
\hline Water & 1 & 0.0095 & & \\
\hline $10 \mathrm{mg} / \mathrm{L}$ & 1 & 0.1884 & 0.1786 & 9.53 \\
\hline Water & 1 & 0.0102 & & \\
\hline Acid Cleaning sample & 100 & 0.0632 & 0.0529 & 278.36 \\
\hline Passivating Sample & 5 & 0.0244 & 0.0136 & 3.39 \\
\hline Water & 1 & 0.0111 & & \\
\hline $7 \mathrm{mg} / \mathrm{L}$ Check Std & 1 & 0.1410 & 0.1295 & 25 \\
\hline Water & 1 & 0.0119 & & \\
\hline
\end{tabular}

\section{Result and Discussion}

Simple and novel spectrophotometric methods are described for simultaneous determination of iron. The UVVisible spectrometer is based on the metal ions-colored complexes (iron I, and iron II) formed by iron with colorimetric reagent 1,10 -phenanthroline that could be monitored

Spectrophotometrically[21]. In all instances, measurements were made at $510 \mathrm{~nm}$ against reagents blank (Figure3, Table 5).

Perkin-Elmer $5100 \quad$ PC Atomic Absorption Spectrophotometer was used with a short part burner and air/acetylene flame optimized with hollow cathode lamp and a single element was measured. The background correction was selectable on an element by element basis. Water had been run between each reading; AA measurements were thus performed. The results of a single method for the detection of iron (Fe) in the Acid Cleaning and Passivating Stainless Solution were obtained and are shown in Figure 4 and Table 7. Calibration curve of iron linear plot of [Fe] concentration against blank-corrected absorbance at $248.3 \mathrm{~nm}$.
Inductively Coupled Plasma Mass Spectrometry ICP/MS and Direct Spectrophotometric method was developed for estimation of Iron (Fe) and successfully used for quantitative extraction of Acid Cleaning (pickling) and Passivating Stainless Steel Solutions at acidic conditions. Since the equilibration time is very less; the method is quick and applicable for determination of Fe from different synthetic mixtures and catalysts. The results obtained are given in Table 8 and show that Fe can be successfully determined by three methods, and instruments.

\section{Conclusion}

The results are presented in Table 8, which reflects the equivalency of the three methods. When AAS, ICP/MS, compared with UV/Vis spectrophotometer is the preferred procedure. Spectrophotometry offers the analyst a relatively inexpensive, simple, fast, and readily available

alternative to more sophisticated techniques for the determination of iron ( $\mathrm{Fe}$ ) in acid cleaning (pickling) and passivating aqueous stainless steel solutions, as well as for quality-control applications. 
Table 8. Results of Iron (Fe) by ICP/MS, UV-Vis, and FAAS.

\begin{tabular}{|c|c|c|c|c|}
\hline \multirow{2}{*}{ Method } & \multirow{2}{*}{ Specification } & \multicolumn{2}{|l|}{ Average Results } & \multirow{2}{*}{$\begin{array}{l}\text { Meet the specifications } \\
\text { (Yes/No) }\end{array}$} \\
\hline & & Pickling (mg/L) & Passivating $(\mathrm{mg} / \mathrm{L})$ & \\
\hline UV-Visible & $20.000 \mathrm{mg} / \mathrm{L} \max$ & 280.25 & 3.91 & Passes \\
\hline ICP-MS & $20.000 \mathrm{mg} / \mathrm{L} \max$ & 277.7 & 3.34 & Passes \\
\hline AAS & $20.000 \mathrm{mg} / \mathrm{L} \max$ & 278.36 & 3.39 & Passes \\
\hline
\end{tabular}

\section{References}

[1] P. Ugo, L. Moretto, A. De Boni, P. Scopece, and G. Mazzocchin, Anal. Chim, Acta, 474, 147-160 (2002).

[2] C. A. Sahin, I. Tokgoz, and S. Berktas, J. Hazard. Mater. 181, 359-365 (2010).

[3] P. M. Harrison, Clin. Toxicol., 4, 529-544 (1971).

[4] B. K. Adebayo, S. Ayejuyo, H. K. Okoro, and B. Ximba, Afr. J. Biotechnol., 10, 16051- 16057 (2013).

[5] ASM Handbook. ASM International Handbook Committee. $\left(10^{\text {th }}\right.$ ed.). Materials Park, Ohio. ISBN 9780871703842. OCLC 21034891.

[6] American Electrorplaters and Surface Finishers Society (2002). Proceedings AESF SUR/FIN 2002: Annual International Technical Conference June 24-27, 2002, Chicago, IL. Orlando, Fl: American Electroplaters and Surface Finishers Society.

[7] Eagleson, Mary (1994). Concise Encyclopedia Chemistry (revised ed.). Walter de Gruyter. p. 834. ISBN 978-3-11011451-5.

[8] Monroe AS9100D\&ISO 9001:2015 2990 Technology Dr. Rochester Hills, MI 48309.

[9] Y. Yildiz, A. Jan, S. Patel. Fluoride Determination in Pickling Solution of Stainless Steel by Ion Selective Electrode World Journal of Applied Chemistry, March 2018.

[10] Bohler Welding Nordic AB. Pickling Handbook. Surface Treatment of Stainless Steel.

[11] Avesta Sheffield Corrosion. Handbook for Stainless Steels, 1999.

[12] ASTM A 380/A380 M-13 Standard Practice for Cleaning, Descaling, and Passivation of Stainless Steel Parts, Equipment, and Systems; ASTM Committee of Standard. ASTM International, 100 Barr Harbor Drive, West Conshohocken, PA, 2013. www.astm.org

[13] Standard Operating Procedures. Determination of Metals by Inductively Coupled Plasma (ICP) Methods. (EPA/SW-846 Methods 30115/3050B/6010B

[14] Y. Yildiz, A. Jan, L. Pendyala, B. Yildiz Determination of Tin in Trityl Candesartan by UV-VIS Spectrophotometer using Phenylfluorone. World Journal of Applied Chemistry, October 20, 2107, 2 (4): 134-13

[15] Y. Yildiz, M. Kotb, A. Hussein, M. Sayedahmed, M. Rachid, M. Cheema Determination of Palladium (II) in 5\% Pd BaSO4 by ICP/MS with Microwave Digestion, and UV-VIS Spectrophotometry. American Journal of Analytical Chemistry, volume 10, Number 4, April 2019.

[16] Michael H. Dunn and B. Hopper. Spectrophotometric Determination of Iron in Acidic Metal-Processing Solutions with 1,10- Phenanthroline Spectroscopy Vol. 2, No: 5.

[17] Harris, D. C. (2003); "Quantitative Chemical Analysis $6^{\text {th }}$ ed.": 18-1, 19-9.

[18] Y. Yildiz, R. Karadag, M. Cordera, B. Gensinger Determination of Manganese in Tricalcium Phosphate (TCP) by Atomic Absorption Spectrometry. American Journal of Chemistry 2020, 11, 301-308.

[19] Russel, B. J., Shelton, J. P. and Wals, A. (1957) An AtomicAbsorption Spectrophotometer and Its Application to the Analysis of Solutions. Spectrochimica Acta, 8, 317. https://doi.org/10.1016/0371-1951(57)80193-3

[20] Koirtyohann, S. R. and Pickett, E. E. (1966) Spectral Interferences in Atomic Absorption Spectrometry. Analytical Chemistry, 38, 585-587. https://doi.org/10.1021/ac60236a015

[21] Z. Marczenco, Separation and Spectrophotometric Determination of Elements (Elis Harwood Limited: Chichester, 1986), 60-66. 